\title{
The effect of the spread of the new COVID-19 on the psychological and social adaptation of families of persons with disabilities in the Kingdom of Saudi Arabia
}

\begin{abstract}
BACKGROUND
Helping families of persons with disabilities in times of the spread of COVID-19 is a major step to ensure their social and psychological adaptation. This call comes from the fact that from a health perspective, persons with disabilities have less immunity and are more vulnerable to deceases and infections. Many families of persons with disabilities have also expressed their concerns regarding the safety of their disabled member/s. Therefore, this study aimed to identify the impact of the new COVID-19 on the psychological and social adjustment of families of persons with disabilities in the Kingdom of Saudi Arabia.
\end{abstract}

\section{PARTICIPANTS AND PROCEDURE}

The sample of the study was chosen randomly from the Asir region. The sample consisted of any member of the families of persons with disabilities (parents and siblings). Participants responded to a questionnaire, which was sent electronically via WhatsApp to the families of persons with disabilities. The questionnaire gathered demographic information about the disabled member from the family (age and level of disability). The questionnaire underwent statistical treatment to extract data for analysis.

RESULTS

The results showed less ability for families of persons with disabilities to adapt psychologically and socially to the spread of COVID-19. The findings revealed the existence of fundamental differences in the levels of psychological and social adaptation among these families due to the level of disability of their member and due to the variable of age, and in favor of the age group of 11-15 years. The study recommended providing safe methods of communication with families of persons with disabilities to reduce the feeling of psychological isolation and loneliness as much as possible during the quarantine or curfew periods.

\section{CONCLUSIONS}

This study explored the levels of psychological and social adaptation of families of persons with disabilities in the time of COVID-19. The spread of the virus created a crisis in different counties and millions of people were infected. Persons with disabilities are among the categories affected most by the infection of the virus due to their weak immunity and their health problems. Therefore, response plans need to take measures that cover the needs of persons with disabilities and their families.

\section{KEY WORDS}

persons with disabilities; COVID-19; psychological and social adaptation 


\section{BACKGROUND}

The outbreak of the new COVID-19 began in China before spreading to the world and caused the death of more than 500 thousand people, with 13,070,095 confirmed cases as of mid-July 2020 (WHO, 2020). COVID-19, in severe cases, can cause pneumonia, acute pneumonia syndrome, failure of different body parts, and sometimes death. Elderly people, persons with disabilities, and people with chronic diseases such as diabetes, asthma and heart disease are among the most vulnerable to infection with the virus. Researchers currently believe that between 5 and 40 cases out of every 1,000 cases of coronavirus will end in death and that the best estimate of the death rate is the death of nine people out of every 1,000 cases or about 1 percent (WHO, 2020). However, this depends on a combination of factors, age group, gender, the general state of a person's health, and the health system.

The new COVID-19 brought an impact on all aspects of life and did not differentiate between ordinary individuals and those with disabilities. Its effect on people with disabilities was more severe, for they suffer from chronic health problems accompanied by weakness in their immune system. All of this raised the concerns of families of persons with disabilities toward the health of their children. It is estimated that persons with disabilities represent 15 percent of the world's population (World Bank, 2020). They are among the most excluded groups in our society and are among the worst affected in this crisis in terms of deaths. Persons with disabilities are less likely to obtain health care, education, work, and participation in society. They are more likely to live in poverty, face higher rates of violence, neglect and abuse, making them among the most marginalized groups in any society affected by the spread of COVID-19 (United Nations, 2020).

The family systems theory states that every member of the family is affected by the events that any member of the family experiences (Broderick, 1993). A child who suffers from any physical or psychological problem affects every member of the family and the family itself as an integrated unit. It changes the family life system and its future goals. For the family to successfully adapt to the emerging epidemic of COVID-19, it should start discussions to learn new roles, and needs to solve communication problems and relationships between its members. Adaptation in these families is related to the degree of cohesion of the parents in their relationship with each other and the degree of harmony between family members. It was found that the efforts made by parents to adapt to the new epidemic of COVID-19 are more effective if the parents' strategies used are balanced or complementary to each other.

The interaction between family members is a very important step toward reducing the impacts of any risks on persons with disabilities (Gold \& Richmond, 1979). Moxley et al. (1989) argued that it is important to promote engaging family members in any kind of intervention. Family members of persons with disabilities receive different kinds of support and services, and the service providers need to support the functioning of the family in hard times. Moreover, family members can help in advocating any intervention programs provided either by the governments or NGOs, which eventually help in the continuation and development of such programs. The process of consulting the family of persons with disabilities is a major factor in identifying the type of services they need and the objectives of any support to the disabled person. In addition, engaging and consulting families of persons with disabilities produce higher functional achievement (Moxley et al., 1989).

Understanding and identifying psychosocial support may be an important factor in stopping the spread of the virus and reducing its consequences for people with disabilities. For example, sharing information about the COVID-19 in terms of its risks, transmission methods, and ways to prevent it is considered an important factor in preventing its outbreak. Therefore, integrating positive mental health messages through social media such as WhatsApp will enhance their social and psychological well-being.

Planning to avoid an outbreak of the new COVID-19 must include the needs of individuals with disabilities, as it is extremely important to maintain physical and psychological health while reducing the risk of infection with the virus. Some measures can be taken by developing communication messages, including providing special pages on social networks that enable visually impaired persons to access and read basic information about the emerging COVID-19. Other measures include developing newsletters and press releases on the outbreak of the new COVID-19, with sign language interpreters.

\section{THE IMPACT OF COVID-19 ON PERSONS WITH DISABILITIES}

The impact of the outbreak of COVID-19 on persons with disabilities is apparent and an expected outcome. Forty-six percent of disabled people are approximately more than 60 years old. In addition, there are around one billion disabled people in the world, $80 \%$ of whom are living in developed and underdeveloped countries (WHO, 2011). The spread of the new COVID-19 epidemic, like other previous pandemics, caused more psychological, social, and physiological stress. The state of being under stress could be temporary, where the individual suffers for a short period and then the stress ends without leaving long-term effects. Stress could also be long term, where persons with disabilities suffer from diseases and chronic health problems 
Mohamad Khasawneh
(Groce, 2005). The psychological and social adaptation among the families of persons with disabilities in the face of COVID-19 helps in promoting psychological and social well-being, for it is considered a form of prevention of the virus. Several groups of disabled people suffer great marginalization. For instance, people with intellectual and psychosocial disabilities do not receive support and services, but rather, they experience abuse and violence.

The common responses of people affected directly or indirectly by COVID-19 show the fear of this epidemic's effect on the well-being of families of persons with disabilities. Some of these responses were the fear of death from the virus and the family's feeling of inability to protect its members from the virus. Families were also afraid of refusing to care for people with disabilities after quarantining their relatives or their carers, the feeling of boredom and isolation, and the fear of deteriorating health status for people with disabilities, especially if their caregivers are quarantined (Thelwall \& Levitt, 2020).

The fear and anxiety resulting from the outbreak of the COVID-19 may lead to enormous psychological pressure on members of society, which constitutes social rejection for people with disabilities because of their fragile immunity and vulnerability to infection with the new COVID-19. Therefore, psychological and social support must be available and be an essential component of any general health response in a manner that is suitable for the needs of this group of society.

COVID-19 did not just bring a health impact on persons with disabilities but also impact on the psychological, social, and economic aspects of this category of people (United Nations, March 2020). As mentioned above, many obstacles face the implementation of protective measures to support persons with disabilities. The vulnerability of persons with disabilities is caused by their special health conditions. Persons with disabilities are more exposed to secondary conditions and other deceases, such as diabetes, obesity, lung issues, and heart disease. These co-morbidities are increased and become worse if the person is infected with COVID-19 (Singh et al., 2020). Providing health care for such a group in the circumstances of the spread of COVID-19, in the appropriate manner, becomes challenging.

Older disabled people are highly affected by the spread of the virus. According to the OECD Health Statistics (2019a, b, c), people with disabilities form the largest group of people who are in a medical institution. In addition, there are also disabled people in prisons, mental institutions, detention institutions, and psychiatric clinics, who receive less support than expected. Such persons with disabilities face barriers in receiving information, support, and appropriate healthcare to prevent them being infected with COVID-19. Comas-Herrera et al. (2020) provide evi- dence that people who are located in institutional settings have higher rates of infection from the virus and even higher rates of deaths.

\section{PRINCIPLES FOR SUPPORTING PERSONS WITH DISABILITY FOR COVID-19}

Any response plan or recovery measures should be based on a human rights approach to include persons with disabilities and their families and avoid the feeling of being left behind. The United Nations insisted on the inclusion of persons with disabilities in the response and recovery plans and programs (United Nations, April 2020). Persons with disabilities have similar needs as other people. Therefore, any support may continue to provide normal services found in any support program for persons with disabilities. However, some principles are important to provide optimal support.

Firstly, non-discrimination is one of the main principles of human rights. Disability should not be any basis of discrimination when providing support to fight COVID-19. It is important to identify the needs of persons with disabilities and anticipate the required support to be provided regardless of gender, age, or the type of disability (Smith, 2019). The second principle is intersectionality, as persons with disabilities experience different kinds of discrimination because of their ethnicity, gender, race, age, legal status, and other factors. Therefore, any response to COVID-19 should pay attention to these discrepancies among persons with disabilities and their families. Another essential principle in supporting persons with disabilities is accessibility to the required facilities and services that such a group needs. Some families might find difficulties and challenges to reach supporting services in the time of quarantine and the curfews happening in different countries (Thelwall \& Levitt, 2020).

There are different barriers to support people with disabilities during the outbreak of the new COVID-19. Firstly, there are environmental obstacles. Many health centers are not available for people with disabilities due to the restrictions imposed by the virus on movement and curfews within cities and villages, which does not allow such people to access health care facilities. Secondly, there are institutional obstacles. The cost of health care for infection with COVID-19 is high. The lack of protocols developed for people with disabilities in quarantine may prevent such people from accessing basic health care. Thirdly, there are personal obstacles. Prejudices against people with disabilities that they cannot contribute to responding to the emerging outbreak of COVID-19 or make their own decisions may lead to additional pressure on people with disabilities and their caregivers. 


\section{PREVIOUS RESEARCH}

Research into the impact of COVID-19 is still scarce and many areas need to be covered. Few empirical studies have been published on the psychological and social adaptation of families of persons with disabilities. The reason behind this is the new emergence of the virus and the lack of information on its cause, treatment, or other related aspects. However, some studies have tackled the impact of COVID-19 on intellectual disabilities and the methods to be used by governments and authorities to include persons with disabilities in response plans.

Skalski et al. (2020) evaluated the relationship between ego-resiliency, social support, coronavirus anxiety, and trauma effects. The study used the Polish adaptation of the Coronavirus Anxiety Scale (CAS). The study was applied to 515 individuals aged 18-78. The results revealed that ego-resiliency and social support were correlated and decreased the severity of the novel coronavirus anxiety. The results also indicated that practitioners should pay attention to the interventions related to improving resiliency and social support to improve mental health during the COVID-19 pandemic.

Tummers et al. (2020) identified full-text articles that contain terms related to intellectual disabilities and applied a text mining technique. The results of this review showed that one hundred fifty-nine articles contained one or more of our specified terms related to ID. The researchers grouped these articles into five groups in terms of five areas: diagnoses and treatments, mental health, viral diseases, genetics, and maternal care and pediatrics. The review suggested that these five areas are important for research concerning COVID-19 and intellectual disabilities.

Pineda and Corburn (2020) suggested a new perspective for ensuring that response plans to COVID-19 should focus on promoting more inclusive and healthy cities for all, including persons with disabilities and their families. Their perspective recommended the following areas to be considered in the response plans: accessible information access, inclusive decision-making, accessibility through continuity of care and social support, economic support, and non-discrimination.

Stankovska et al. (2020) reviewed different studies and experiences that tackled the connection between depression, stress, anxiety, and viral diseases such as COVID-19. The review concluded that any psychological intervention should take into consideration the importance of engaging communities in the different stages of the interventions and improving the care system of vulnerable groups of persons, especially persons with disabilities.

Sivashanker et al. (2020) developed a pragmatic COVID-19 exposure disclosure checklist to help workers who support patients and families in the time of the COVID-19 outbreak. The study identified five core competencies that are important, which are risk management, clinical, language, psychosocial, and infectious disease. The purpose is to train facilitators on this checklist to help support families. These measures are now implemented and used in Brigham and Women's Hospital, Boston. The study proved that using such categorization is helpful to identify areas of support to provide for patients and families.

Brooks et al. (2020) reviewed the psychological impact of quarantine. The review found (3166) papers in different databases, from which 24 were included in this review. The result of the review showed that the majority of these articles reported negative psychological effects, such as confusion, anger, and posttraumatic stress symptoms. The review also found the existence of stressors, such as frustration, infection fears, inadequate supplies, boredom, and financial loss. The review suggested that when quarantine is important, it should be for sufficient time that does not affect the psychological and mental well-being of people.

These studies tackled the impact of COVID-19 on people in general and persons with disabilities in specific. It is notable that there are psychological and social consequences for the spread of the virus, whether for those infected, people in quarantine, or those at home in times of curfew. The present study attempted to investigate such impacts on the families of persons with disabilities in the Kingdom of Saudi Arabia in terms of the psychological and social impact on these families as they support their disabled members.

The problem of the study is related to the emergence of the new COVID-19 virus around the world, which made people with disabilities and their families more vulnerable to the virus. From a health perspective, persons with disabilities are among the most vulnerable categories in any society. Therefore, they require urgent psychological and social support in addition to medical support. There is a research gap in addressing the issue of psychosocial and social support to families of people with disabilities in times of epidemics, such as COVID-19. The virus is new and the effects on families of persons with disabilities are also new to the field. Coping with the crisis is one of the major issues to address to provide relief and support to these families. Therefore, this study attempts to fill this gap and investigate the effect of the spread of the virus on these families to provide more insights to decision-makers.

The results obtained from this study will be significant for two reasons. The first is the theoretical aspect. Studying the psychological and social adaptation of families of persons with disabilities reveals different issues to be discussed. Families are expected to comply with the regulations of preventing infec- 
Mohamad Khasawneh tion with the virus and they are obligated to prevent falling into psychological and social anxiety and isolation. The second is the practical significance, which stems from determining the extent to which families of persons with disabilities need a system of psychological and social adaptation to facilitate a safe and stable psychological and social life in a world of successive variations due to the spread of the COVID-19. Therefore, this study seeks to evaluate the effect of the spread of COVID-19 on the psychological and social adjustment of families of persons with disabilities and to obtain statistical descriptive indications about the variables related to people with disabilities such as type of disability and age.

To address the problem, this study aims to achieve the following objectives:

- To identify the impact of the emergence of the new COVID-19 on the psychological and social adjustment of families of persons with disabilities in the Kingdom of Saudi Arabia.

- To identify the effect of the type of disability variable on the level of psychological and social adjustment behavior among families of persons with disabilities in the Kingdom of Saudi Arabia in light of the impact of the spread of the new COVID-19.

- To identify the effect of the age variable of the disabled on the level of psychological and social adjustment behavior among families of persons with disabilities in the Kingdom of Saudi Arabia in light of the impact of the spread of the new COVID-19. In order to achieve the objectives of the study, the following hypotheses were tested:

- There are no statistically significant differences (at $\alpha<.05)$ in the level of psychological and social adaptation of families of persons with disabilities in the Kingdom of Saudi Arabia after the spread of COVID-19.

- There are no statistically significant differences (at $\alpha<.05)$ in the level of psychological and social adaptation of families of persons with disabilities in the Kingdom of Saudi Arabia according to the level of disability after the spread of COVID-19.
- There are no statistically significant differences (at $\alpha<.05)$ in the level of psychological and social adaptation of families of persons with disabilities in the Kingdom of Saudi Arabia according to the age of the disabled after the spread of COVID-19.

\section{PARTICIPANTS AND PROCEDURE}

\section{PARTICIPANTS}

The study population consisted of all families of persons with disabilities in the Asir region in Saudi Arabia. Because of the difficulties of reaching more families in the area, the study selected 100 families of persons with disabilities randomly. Families responded to the adaptive psychological and social behavior questionnaire (Table 1). The families were asked about the level of disability its member has to face, connecting the psychological and social adaptation to the severity of the disability. This kind of inquiry helps in identifying the levels of adaptation and the needs (or no needs) to intervene.

\section{RESEARCH INSTRUMENT}

The research instrument used in this study was a questionnaire consisting of 20 paragraphs written in positive formats and using a five-point Likert scale. In this type of scale, respondents choose between strongly agree (5 points), agree (4 points), hesitant (3 points), disagree (2 points), and strongly disagree (1 point). A score of (85) and above represented a high level and a score below (85) represented a low level (see Appendix).

The validity of the scale means the ability of the scale to answer the questions of the study (Thorndike et al., 1991). The validity of the questionnaire has been evaluated by presenting it to ten experts working in the field of education, who reviewed the questionnaire and provided their feedback. Their sug-

Table 1

Distribution of the study sample according to age, variables and percentages

\begin{tabular}{lllc}
\hline Variables & \multicolumn{1}{c}{ Level of variables } & $N$ & Percentage \\
\hline $\begin{array}{l}\text { Level of disability of the disabled } \\
\text { member }\end{array}$ & Simple & 40 & $40 \%$ \\
& Moderate & 50 & $50 \%$ \\
& Severe & 10 & $10 \%$ \\
Age of the disabled member & $1-10$ years & 30 & $30 \%$ \\
& $11-15$ years & 60 & $60 \%$ \\
& More than 15 years & 10 & $10 \%$ \\
\hline
\end{tabular}


gestions, comments, and changes were considered accordingly. All items were revised and approved by judges in terms of word usage and the relevance of the content. Based on the judges' suggestions, one item was deleted from the questionnaire and two items were added. Paragraphs were revised until all judges approved the phrases used and the correctness of the content. The validity indicators of the scale were verified by running an exploratory study on a sample of 20 families similar to the population of the study. The paragraphs of the questionnaire were analyzed and the coefficient of discrimination of each paragraph was calculated. The coefficient of discrimination is an indicator of validity for each paragraph in the form of a correlation coefficient between each paragraph and its associated variable. The correlation coefficient was in the range .63-.86, which represented statistical significance at the level of $p=.05$, and therefore, the scale can be considered generally valid (Table 2 ).

The reliability of the scale was determined using the test-retest method by applying it to a pilot study of 20 families of persons with disabilities. The Pearson correlation coefficient between scores was calculated on the two tests. The Spearman correlation coefficient using the return method was .83 for the scale as a whole. The stability coefficient was calculated using the Cronbach's $\alpha$, and the final internal consistency coefficient was .90 , which indicated that the scale has an appropriate level of reliability.

\section{DATA COLLECTION AND ANALYSIS}

The researcher collected data from 100 families of persons with disabilities in the Asir region in Saudi Arabia. First, an electronic version of the questionnaire was created and sent to those families who have been contacted and notified via WhatsApp. Using the WhatsApp application was easier to send the questionnaire and families were able to respond quickly as they have smartphones and can access the research instrument in this study. There were 100 returned questionnaires, which were ready for statistical analysis as described in the next section.

After collecting the returned, answered questionnaires, data were recorded and tabulated with the assistance of SPSS for Windows 17.0 to identify the correlated relationships of variables concerning using the socio-psychological adaptation scale. Different statistical methods were used to achieve the main objectives of the present investigation. These methods included descriptive statistics, independent sample $t$-test, and analysis of variance (ANOVA). Descriptive statistics, including mean scores, standard deviation, and frequencies, were computed to summarize the responses of families of persons with disabilities according to their social and psychological
Table 2

Correlation coefficients of the paragraphs to the overall score of the scale

\begin{tabular}{cccc}
\hline Paragraph & $\begin{array}{c}\text { Correlation } \\
\text { coefficients }\end{array}$ & Paragraph & $\begin{array}{c}\text { Correlation } \\
\text { coefficients }\end{array}$ \\
\hline 1 & .69 & 9 & .63 \\
2 & .70 & 10 & .84 \\
3 & .79 & 11 & .78 \\
4 & .68 & 12 & .86 \\
5 & .83 & 13 & .67 \\
6 & .72 & 14 & .71 \\
7 & .77 & 15 & .78 \\
8 & .76 & & \\
\hline
\end{tabular}

New COVID-19

adaptation after the spread of COVID-19 concerning age and level of disability.

An independent sample $t$-test is a statistical method employed to evaluate the difference between the mean scores of two groups of a variable. In the current study, this statistical method was used to identify the significant differences in the responses of families of persons with disabilities in the Kingdom of Saudi Arabia on the socio-psychological adaptation scale. An analysis of variance (ANOVA) is a method of statistical analysis used to determine differences among the means of more than two groups of a variable (Corbin \& Strauss, 2014). In the present study, this statistical method was used to determine the impact of the spread of COVID-19 on the social and psychological adaptation of families of persons with disabilities in the Kingdom of Saudi Arabia in terms of the age of the disabled and the level of disability.

\section{RESULTS}

This section presents the findings obtained from the statistical analysis by discussing results related to the hypotheses of the study.

First hypothesis: "There were no statistically significant differences (at $\alpha<.05)$ in the level of psychological and social adaptation of families of persons with disabilities in the Kingdom of Saudi Arabia after the spread of COVID-19".

To prove this hypothesis, mean scores and standard deviations for the level of psychological and social adaptation among families of persons with disabilities who have adaptive behavior were calculated according to the criterion specified in the study. The levels of adaptation were divided according to adaptive behaviors into a high level of adaptation and 
low level of adaptation. The results are presented in Table 3.

The results in the previous table indicated the rejection of the first hypothesis in question, which means that there are fundamental differences in the

\section{Table 3}

Results of the t-test for the levels of psychological

Mohamad Khasawneh and social adaptation among families of persons with disabilities who have high and low adaptive behavior

\begin{tabular}{lcccc}
\hline $\begin{array}{l}\text { Level of adaptive } \\
\text { behavior }\end{array}$ & $N$ & $M$ & $S D$ & $p$ \\
\hline $\begin{array}{l}\text { Level of high } \\
\text { adaptive behavior }\end{array}$ & 30 & 3.62 & 0.64 & .837 \\
$\begin{array}{l}\text { Level of low } \\
\text { adaptive behavior }\end{array}$ & 70 & 2.56 & 0.75 & \\
\hline
\end{tabular}

\section{Table 4}

Results of the levels of psychological and social adaptation for families of persons with disabilities according to the level of disability

\begin{tabular}{lccc}
\hline Level of disability & $N$ & $M$ & $S D$ \\
\hline Simple & 40 & 3.51 & 0.63 \\
Moderate & 50 & 2.63 & 0.79 \\
Severe & 10 & 2.34 & 0.56 \\
\hline
\end{tabular}

levels of psychological and social adaptation among families of persons with disabilities attributable to the extent of their orientation towards adaptive and social behavior. The significance was in favor of families with a low level of adaptive and social behavior, where these families showed less ability to adapt psychologically and socially. This result agrees with Brooks et al. (2020) in their investigation of the psychological impact of quarantine. Their results showed the existence of stress and anxiety because of the spread of the virus.

Second hypothesis: "There were no statistically significant differences (at $\alpha<.05)$ in the level of psychological and social adaptation of families of persons with disabilities in the Kingdom of Saudi Arabia according to the level of disability after the spread of COVID-19”.

To identify the levels of psychological and social adaptation for families of persons with disabilities, according to the variable of the level of disability, the mean scores and standard deviations were calculated as shown in Table 4.

To identify the significance of the differences between these mean scores and verify the hypothesis, the ANOVA test was used for the level of psychological and social adaptation of families of persons with disabilities according to the level of disability as shown in Table 5.

The results in the previous table indicate the rejection of the second hypothesis in question, which means that there are significant differences in the levels of psychological and social adaptation in families of persons with disabilities attributable to the level of the disability. To identify the direction of

Table 5

Results of ANOVA analysis of the level of psychological and social adaptation of families of persons with disabilities according to the level of disability

\begin{tabular}{lccccc}
\hline Source of variance & Sum of squares & Freedom value & Mean square & $F$ & $p$ \\
\hline Between levels & 0.35 & 3 & 0.12 & 4.93 & .003 \\
Within levels & 2.32 & 97 & 0.02 & & \\
Total & 2.68 & 100 & & & \\
\hline
\end{tabular}

Table 6

Results of Scheffe test for the post hoc comparisons of the psychological and social adaptation scores for families of persons with disabilities according to the level of disability

\begin{tabular}{lcccc}
\hline Level of disability & $M$ & Simple & Moderate & Severe \\
\hline Simple & 3.51 & & $*$ & $*$ \\
Moderate & 2.63 & $*$ & $*$ \\
Severe & 2.34 & $*$ & $*$ & \\
\hline
\end{tabular}

Note. ${ }^{*}$ significant at $p<.05$. 
these differences, the Scheffe test was used as shown in Table 6.

It is clear from the previous table that there are significant differences in the post hoc comparisons of the scores of the levels of psychological and social adaptation of families of persons with disabilities according to the level of disability. The difference was in favor of families of persons with simple disabilities. The level of adaptive behavior of these families was low. They showed less ability to adapt psychologically and socially because their sons are vulnerable and exposed to the virus. In addition, these disabled persons have low immunity and might have chronic diseases accompanying their disability. This leaves the family in constant fear and anxiety that their children will be exposed to the new COVID-19.

Third hypothesis: "There were no statistically significant differences in the level of psychological and social adaptation of families of persons with disabilities in the Kingdom of Saudi Arabia according to the age of the disabled after the spread of COVID-19".

To identify the levels of psychological and social adaptation of families of persons with disabilities according to the age variable of the disabled, mean scores and standard deviations were calculated, as shown in Table 7.

To determine the significance of the differences between these scores and verify the hypothesis, the ANOVA test was used as shown in Table 8.

It is clear from the previous table that there are statistically significant differences in the scores of psychological and social adaptation of families of persons with disabilities attributable to the age vari- able. To determine the direction of these differences, the Scheffe test was used for the post hoc scores as shown in Table 9.

It is clear from the previous table that there are fundamental differences in the post hoc scores of the psychological and social adaptation of families of persons with disabilities according to the age variable. The differences were in favor of the age group of 11-15 years, which means that this category showed a high adaptation level compared to other age groups. The reason behind this may be attributed to the stability of the health status of this age group compared to the age group 1-10 years in which the family is more worried because it is a recent incident the family witnessed, because the health status of the children of these families is still a source of worry, which causes a decrease in the psychological and social adaptation of the families of this group. Previous investigations proved the existence of such an impact, not only on the disabled person but also on the family in general

\section{Table 7}

Results of the level of psychological and social adaptation of families of persons with disabilities according to the age of the disabled

\begin{tabular}{lccc}
\hline Age of the disabled & $N$ & $M$ & $S D$ \\
\hline 1-10 years & 30 & 2.25 & 0.75 \\
11-15 years & 60 & 3.41 & 0.65 \\
More than 15 years & 10 & 2.32 & 0.66 \\
\hline
\end{tabular}

\section{Table 8}

Results of ANOVA analysis of the level of psychological and social adaptation of families of persons with disabilities according to the age of the disabled

\begin{tabular}{lccccc}
\hline Source of variance & Sum of squares & Freedom value & Mean square & $F$ & $p$ \\
\hline Between age groups & 0.42 & 3 & 0.14 & 6.78 & $<.001$ \\
Within age groups & 1.99 & 97 & 0.02 & & \\
Total & 2.40 & 100 & & \\
\hline
\end{tabular}

\section{Table 9}

Results of Scheffe test for the post hoc comparison of the psychological and social adaptation scores for families of persons with disabilities according to the age variable

\begin{tabular}{lcccc}
\hline Age of the disabled & $M$ & $1-10$ years & $11-15$ years & More than 15 years \\
\hline $1-10$ years & 2.25 & $*$ & $*$ \\
$11-15$ years & 3.41 & & \\
More than 15 years & 2.32 & & \\
\hline Note. ${ }^{\text {significant at } p<.05 .}$ &
\end{tabular}


Mohamad Khasawneh
(Skalski et al., 2020; Tummers et al., 2020; Stankovska et al., 2020; Brooks et al., 2020).

In the case of families of persons with disabilities of the age group more than 15 years, they have low levels. This could be explained by the decrease in immunity and chronic diseases shown by the members of these families and their involvement in long treatment programs, along with the accompanying side effects on them (Pineda \& Corburn, 2020). This all leads the families of this group to be concerned about their children. Eventually, the level of psychological and social adaptation will be lower than others.

\section{CONCLUSION AND RECOMMENDATIONS}

This study explored the levels of psychological and social adaptation of families of persons with disabilities in the time of COVID-19. The spread of the virus created a crisis in different counties and millions of people were infected. Persons with disabilities are among the categories affected most by infection with the virus due to their weak immunity and their health problems. Therefore, response plans need to take measures that cover the needs of persons with disabilities and their families.

This study concluded that the adaptive and social behavior shown by families of persons with disabilities is necessary and beneficial, especially for families which have disabled persons in the age groups of 1-11 years and more than 15 years. Having a person with disabilities causes psychological pressure on these families because they strive to protect their children. Communication with families of persons with disabilities is an urgent measure to help them face the dangers of the spread of COVID-19, promoting their mental health and preventing the spread of infection.

Based on the results obtained, this study recommends including persons with disabilities in all COVID-19 response plans and programs. Persons with disabilities and their families need to have access to all kinds of facilities, services, and information related to COVID-19. Moreover, authorities may provide free applications for families of persons with disabilities to obtain psychological and social support easily and conveniently. In addition, officials can provide safe methods of communication to reduce feelings of psychological isolation and loneliness as much as possible during the quarantine period. It is also important to suggest and provide activities for families of persons with disabilities during the quarantine period to reduce stress and related symptoms. Finally, community-based organizations, the Department of Education, and King Khalid University should be beneficial partners in providing support within the framework of mental health and psychosocial sup- port to persons with disabilities and their families in the light of the COVID-19 pandemic.

\section{LIMITATIONS AND FUTURE RESEARCH}

This study was limited to a selected sample from families of persons with disabilities only. This study was applied in the Asir region in the Kingdom of Saudi Arabia in the period March-April 2020. The generalization of the results is limited to these delimitations. Future research could focus on a wider sample. Researchers could conduct studies in different areas as well in the Kingdom of Saudi Arabia to measure the impact of COVID-19 on the whole country.

\section{ACKNOWLEDGMENTS}

This study was sponsored by the Research Group Program of the Scientific Deanship at King Khalid University, Kingdom of Saudi Arabia (R.G.P.IL34L40).

\section{REFERENCES}

Broderick, C. B. (1993). Understanding family process: Basics of family systems theory. Sage Publications.

Brooks, S. K., Webster, R. K., Smith, L. E., Woodland, L., Wessely, S., Greenberg, N., \& Rubin, G. J. (2020). The psychological impact of quarantine and how to reduce it: Rapid review of the evidence. The Lancet, 395, 912-920. https://doi.org/10.1016/ S0140-6736(20)30460-8

Comas-Herrera, A., Zalakain, J., Litwin, C., Hsu, A. T., Lane, N., \& Fernández, J. L. (2020). Mortality associated with COVID-19 outbreaks in care homes: Early international evidence. International Long-Term Care Policy Network. Retrieved from https://tccovid.org/2020/04/12/mortality-associated-withcovid-19-outbreaks-in-care-homes-early-international-evidence/

Corbin, J., \& Strauss, A. (2014). Basics of qualitative research: Techniques and procedures for developing grounded theory. Sage Publications.

Gold, P., \& Richmond, L. J. (1979). Counseling parents of learning disabled children. Elementary School Guidance \& Counseling, 14, 16-21.

Groce, N. E. (2005). HIV/AIDS and individuals with disabilities. Health and Human Rights, 8, 215-224.

Moxley, D. P., Raider, M. C., \& Cohen, S. N. (1989). Specifying and facilitating family involvement in services to persons with developmental disabilities. Child and Adolescent Social Work Journal, 6, 301-312. https://doi.org/10.1007/BF00755223

OECD Health Statistics (2019a). Beds in residential long-term care facilities. Retrieved from https:// oe.cd/ds/health-statistics 
OECD Health Statistics (2019b). Long-term care beds in hospitals. Retrieved from https://oe.cd/ds/ health-statistics

OECD Health Statistics (2019c). Psychiatric care beds in hospitals. Retrieved from https://oe.cd/ds/ health-statistics

Pineda, V. S., \& Corburn, J. (2020). Disability, urban health equity, and the coronavirus pandemic: Promoting cities for all. Journal of Urban Health, 97, 336-341. https://doi.org/10.1007/s11524-02000437-7

Sivashanker, K., Mendu, M. L., Wickner, P., Hartley, T., Desai, S., Fiumara, K., Resnick, A., \& Salmasian, H. (2020). Communication with patients and families regarding healthcare-associated exposure to coronavirus 2019: a checklist to facilitate disclosure. The Joint Commission Journal on Quality and $\mathrm{Pa}$ tient Safety, 46, 483-488. https://doi.org/10.1016/j. jcjq.2020.04.010

Singh, A. K., Gupta, R., \& Misra, A. (2020). Comorbidities in COVID-19: Outcomes in hypertensive cohort and controversies with renin angiotensin system blockers. Diabetes \& Metabolic Syndrome: Clinical Research \& Reviews, 14, 283-287. https:// doi.org/10.1016/j.dsx.2020.03.016

Skalski, S., Uram, P., Dobrakowski, P., \& Kwiatkowska, A. (2020). The link between ego-resiliency, social support, SARS-CoV-2 anxiety, and trauma effects. Polish adaptation of the Coronavirus Anxiety Scale. PsyArXiv, preprint. https://doi.org/10.31234/ osf.io/28tnw

Stankovska, G., Memedi, I., \& Dimitrovski, D. (2020). Coronavirus COVID-19 disease, mental health, and psychosocial support. Society Register, 4, 33-48. https://doi.org/10.14746/sr.2020.4.2.03

Smith, J. (2019). Overcoming the 'tyranny of the urgent': Integrating gender into disease outbreak preparedness and response. Gender \& Development, 27, 355-369. https://doi.org/10.1080/135520 74.2019.1615288

Tummers, J., Catal, C., Tobi, H., Tekinerdogan, B., \& Leusink, G. (2020). Coronaviruses and people with intellectual disability: an exploratory data analysis. Journal of Intellectual Disability Research, 64, 475-481. https://doi.org/10.1111/jir. 12730

Thelwall, M., \& Levitt, J. M. (2020). Retweeting Covid-19 disability issues: Risks, support, and outrage. El profesional de la Información, 29, e290216. https://doi.org/10.3145/epi.2020.mar.16

Thorndike, R. M., Cunningham, G. K., Thorndike, R. L., \& Hagen, E. P. (1991). Measurement and evaluation in psychology and education. Macmillan Publishing Co, Inc.

United Nations (April 2020). COVID-19 and human rights: We are all in this together. Retrieved from https://www.un.org/sites/un2.un.org/files/un policy_brief_on_human_rights_and_covid_23_ april_2020.pdf [accessed May 15, 2020]
United Nations (March 2020). Shared responsibility, global solidarity: Responding to the socio-economic impacts of COVID-19. Retrieved from https://unsdg.un.org/resources/shared-responsibility-globalsolidarity-responding-socio-economic-impactscovid-19

United Nations (2020). Policy brief: a disability-inclusive response to COVID-19. Retrieved from https:// unsdg.un.org/resources/policy-brief-disabilityinclusive-response-covid-19

WHO (2011). World report on disability 2011. World Health Organization.

WHO (2020). Disability considerations during the COVID-19 outbreak. World Health Organization.

World Bank (2020). Disability inclusion. Retrieved from https://www.worldbank.org/en/topic/disability [accessed July 15, 2020] 


\section{THE PSYCHOLOGICAL AND SOCIAL ADAPTATION SCALE FOR FAMILIES OF PERSONS WITH DISABILITIES}

Dear Sir/Madam,

Greetings,

The researcher is conducting a study aiming to reveal the impact of the new COVID-19 on psychological and

Mohamad Khasawneh social adaptation of families of persons with disabilities in the Kingdom of Saudi Arabia. Please add X in the box that represents the level of your psychological and social adaptation. The results of the current study will be used for scientific and academic purposes only. There is no need to mention the name and place of work, which gives you complete freedom to answer. There is no right or wrong answer, but the correct answer expresses your true point of view.

Please fill in the following information:

Disabled person:

Level of disability:

Father

Simple

Age of the disabled person: 1-10 years

Mothe

Moderate

10-15 years
Daughter

Severe

more than 15 years

Best regards,

The researcher 


\begin{tabular}{|c|c|c|c|c|c|c|c|}
\hline No. & Paragraph & $\begin{array}{l}\text { Strongly } \\
\text { disagree }\end{array}$ & Disagree & $\begin{array}{c}\text { Somewhat } \\
\text { disagree }\end{array}$ & $\begin{array}{c}\text { Somewhat } \\
\text { agree }\end{array}$ & Agree & $\begin{array}{c}\text { Strongly } \\
\text { agree }\end{array}$ \\
\hline
\end{tabular}

1. I am very worried about my child getting infected with the coronavirus

2. I did not adapt to the spread of the new coronavirus

3. My mood fluctuates between sadness and pleasure under the conditions related to the spread of the coronavirus

4. I am not comfortable with the social situations around me under the circumstances related to the spread of the coronavirus

5. I believe that the future is not better than the present under the circumstances related to the spread of the coronavirus

6. I have a feeling of hatred for others under the conditions related to the spread of the coronavirus

7. I lack self-confidence because I have a disabled child

8. I feel that the spread of coronavirus has caused me isolation

9. I feel that my child will not survive the new coronavirus

10. I feel unable to protect my child from the emerging coronavirus

11. I feel unable to deal with my child in light of the spread of the new coronavirus

12. I feel that I did not get full support in the spread of the new coronavirus

13. I feel the consistency of applying health instructions related to a child in light of the spread of the new coronavirus

14. I feel like a family of a disabled child who has been left behind, and I have not received the required care

15. The spread of the new coronavirus helped to integrate the family with the families of ordinary children 